\title{
Students' Error Analysis in Solving The Math Word Problems of High Order Thinking Skills (HOTS) Type on Trigonometry Application
}

\author{
$1^{\text {st }}$ Muhammad Darmawan Dewanto \\ Department of Mathematics Education, \\ Faculty of Teacher Training and \\ Education, \\ Sebelas Maret University \\ Surakarta, Indonesia \\ darmawandewanto.mdd@gmail.com
}

\author{
$2^{\text {nd }}$ Budiyono \\ Department of Mathematics Education, \\ Faculty of Teacher Training and \\ Education, \\ Sebelas Maret University \\ Surakarta, Indonesia \\ budiyono53@yahoo.com
}

\author{
$3^{\text {rd }}$ Hasih Pratiwi \\ Department of Mathematics, \\ Faculty of Teacher Training and \\ Education, \\ Sebelas Maret University \\ Surakarta, Indonesia \\ hasihpratiwi@gmail.com
}

\begin{abstract}
An endeavour to improve the quality of education have been made by improving the implementation of learning. The effort has not been enough to show satisfactory results. This can be seen from the mathematics learning achievement shown by the students still low. Based application PAMER UN 2017 by PUSPENDIK, Mathematics National Exam problems that have the lowest absorption is on trigonometry application. This study aimed to find out the errors of students in solving the HOTS type problem in the application of trigonometry. The type of this research is qualitative descriptive research. The subjects of the research are 189 students from three Vocational High Schools in Gunungkidul Regency, Indonesia, with high, medium and low school category using stratified cluster random sampling technique. To collect the data, this research conducted observations, tests, and interviews. Data analysis techniques include data reduction, triangulation of data that was compared with data result of observation, test, and result of interviews. The results of the analysis show there were three types of errors, namely error type I (understand the meaning of the problem), error type II (applying the concept), and error type III (calculating). The cause of student error type I was lack of understanding the meaning of the problem to make mathematical modeling. In the error type II, students have difficulties distinguishing between $V$-shaped depression and elevation, students were confused to use the concepts and formulas. Error type III is when the students were not precise in the calculations or in a hurry to do the problem.
\end{abstract}

\section{INTRODUCTION}

Mathematics is a universal science that underpins the development of modern technology that has an essential role in various disciplines and develops the human mind power. Abstract mathematical concepts correlate with each other to form new and more complex concepts [1]. The students are introduced to things that are abstract in order to shape the concept of new mathematical knowledge. Many assume that mathematics is difficult because mathematics is identical to a series of numbers, symbols, and formulas that can be solved through mathematical arithmetic operations. Of course, this will affect the student's mathematics learning achievement.

Efforts to improve the quality of education have been made by enhancing the implementation of learning. However, the effort has not been enough to show satisfactory results. This can be seen from the mathematics learning achievement shown by the students still low. The fact was supported by the students' mathematics achievement which is still low. The low achievement of students' mathematics learning can be seen in the report of the National Examination of Vocational High School of 2017 as the following table (Table 1).

Keywords—students, error analysis, Higher order thinking skills, trigonometry,

TABLE I._REPORT OF NATIONAL EXAMINATION RESUlt OF Vocational High SCHOOL IN INDONESIA YeaR 2017

\begin{tabular}{cccccc} 
National Exam Score & Indonesian & English & Mathematics & competence & Total Average \\
& & & & & \\
\hline Average & 64.23 & 40.35 & 36.81 & 73.59 & 214.98 \\
Category & $\mathrm{C}$ & $\mathrm{D}$ & $\mathrm{D}$ & $\mathrm{B}$ & $\mathrm{D}$ \\
\hline
\end{tabular}

Based on Table 1, it can be seen that the average of the national exam score of all mathematics subjects of the vocational high school in Indonesia in the academic year of 2017 was 36.81 with the D category. The same problem is also found in Yogyakarta Special Region. Based on the report of mathematics national exam results of Vocational High School lesson year 2017 in the following table (Table II).

table iI. Average Result of Mathematics National Exam of Vocational High School in D.I. Yogyakarta 


\begin{tabular}{cccc}
\hline $\begin{array}{c}\text { Average Result of UN Mathematics Vocational } \\
\text { High School in D.I. Yogyakarta }\end{array}$ & $\mathbf{2 0 1 5}$ & $\mathbf{2 0 1 6}$ & $\mathbf{2 0 1 7}$ \\
\hline Average & 55,30 & 48,53 & 49,23 \\
Category & C & D & D \\
\hline
\end{tabular}

Concerning to the national exam results of Vocational High School in Table 2 during the last three years, it can be seen that the results of Mathematics National Exam subjects are quite low. The average mathematics test score in 2015 was 55,30 with $\mathrm{C}$ category. In 2016 there was a decrease in the average mathematics test score to 48,53 under category D. The result of mathematics exam test in 2017 was not

TABLE III. A REPORT OF NATIONAL EXAMINATION VocATIONAL High SCHOOL YeAR 2017 In GUNUNGKIDUL REgENCY

\begin{tabular}{cccccc}
\hline National Exam Score & Indonesian & English & Mathematics & competence & Total Average \\
\hline Average & 72.98 & 45.81 & 50.43 & 76.94 & 246.16 \\
Category & $\mathrm{B}$ & $\mathrm{D}$ & $\mathrm{D}$ & $\mathrm{B}$ & $\mathrm{D}$ \\
\hline
\end{tabular}

Table III shows that the gained score is categorized low (50.43). Based on the application of "PAMER UN 2017" by PUSPENDIK, of the 40 Mathematics National Exam problems that have the lowest absorption is on trigonometric material with the indicator "students can solve contextual problems in trigonometry" that is only $36.07 \%$ of students who answered correctly from 38 schools.

The observations results on learning mathematics in some schools both being in the process of learning is in class $\mathrm{X}$, the material application of trigonometry, many mathematical stories that experienced errors in mathematical communication, errors applying concepts, and count.

Word problems have for long been a significant part of school mathematics for many reasons. For instance, they provide opportunities for students to use mathematical tools to promote the link between mathematics and real-life context, use thinking and problem-solving heuristics, and provide a platform to develop new concepts and skills [2]. Different types of word problems have been the focus of much analytical and empirical research in the past, for instance, in the classification of addition and subtraction word problems [3] and multiplication or division situations [4]. The multi-step word problem is another type which involves two or more steps in the solving process. Studies reported that solving a mathematical word problem with two or more steps create more difficulty in obtaining the right answers [5].

Research evidence showed that for mathematical problems solving, the most significant deficiency seems to be in problem representation processes and strategies, which are critical to practical problem solving [6]. Stressed the importance of problem representation strategies to process linguistic and numerical information, comprehend and integrate the information from internal representations in memory and develop solution plans [7].

Of these problems of course required further analysis of student error in solving the problem of the application on the principal trigonometry topic. In this study, the problem is limited to the error of students solving the story problem on the application of trigonometric, material comparison trigonometric.
Mathematical stories are the most commonly used in mathematics problem, so each student must interpret them before they can count the answers [8]. Problem stories often pose challenges because they require students to read and understand problem texts, identify questions that need to be answered and eventually create and solve mathematical equations [9]. These problems are usually demanding students to think high level.

Higher Order Thinking Skills is the process of thinking how to find answers and solutions in difficult and challenging situations by picking up and connecting new and trapped knowledge to provide broader knowledge [10]. HOTS in Bloom's taxonomy, including categories of cognitive analysis, evaluation, and creation. HOTS is divided into two components, critical thinking and creative thinking [11]. Based on [10] and [11] it can be concluded that HOTS is the ability to solve problems in new situations using knowledge. Such capabilities are critical thinking, creativity and problem-solving abilities that are indicators of higherorder thinking.

Taken from the revised version of Bloom's taxonomy, HOTS have defined by three levels of upper-level cognitive skills in the learning hierarchy: analyze, evaluate, and create. The analysis refers to the ability of learners to deconstruct their knowledge structures and categories into their respective groups and identify relationships between components of knowledge structures [12]. High-level thinking skills are the ability of students to complete tasks with reasoning, which require justification or explanation for more than one possible solution [13]. In Bloom's Taxonomy, students' abilities involve analysis, evaluation, and manufacture that are considered to be high-thinking skills [14]. With this ability, students are expected to connect to various instructions (instructions) and facts with their knowledge to make predictions of the result. Bloom's Taxonomic Revision states that indicators can measure highlevel thinking skills analyzing (formulating problems, hypotheses, and collecting data), evaluating (analyzing data and conclusions), and shaping (shaping products) [15].

The analysis is the investigation of an entity (e.g., essay, attitude) to find out what causes it, how to sit the case, and 
partly. While the error is about wrong, mistake, negligence. So an error analysis is an investigation of an event to look for the cause of the error or the error [16]. Causes of mistakes made by students in working on mathematical story problems are errors related to language, errors in the mastery of concepts and facts in mathematics, errors in using formulas or traits [17]. This study aimed to find out the errors of students in solving the HOTS type problem in the application of trigonometry.

\section{METHODS}

This study is qualitative descriptive research. The population of this research is all students of Vocational High School in Gunung kidul Regency Yogyakarta, while the subject is class $\mathrm{X}$ students from three schools in Gunung kidul Regency Yogyakarta. Three categories of schools are obtained based on the national examination score in 2017 using stratified cluster random sampling technique. The results of the categorization show there are nine schools with a high category, 15 schools in the medium category, and 14 schools with a low category. From each of these categories, is selected a school to serve as a study sample based on school accreditation and the average grade of the school. The subjects of this study were 189 students, each of 61 students from high and low school, and 67 students from medium categorized school. The research was conducted in the second semester of academic year 2017/2018.

The data collection method used observation, test, and interview. Data analysis techniques include data reduction, triangulation of data that was compared with analysis data result of observation, test, and result of interviews. The test instruments are four problems as follows:

(1) Two vocational high school students are observing a 30 meters high building. If the two students look at the top of the building from two opposite areas with the elevation angles of 30 and 45 respectively, determine the distance between the two students!

(2) From the top of a tower as high as 36 meters, two vessels are in a position in the east on the corner of depression $30^{\circ}$ and $60^{\circ}$. Determine the distance of both ships!

(3) Nur Rohman stands between the tower and the tree. The distance between Nur Rohman to the tower and the trees in a row is 24 meters and 12 meters. Meanwhile, the elevation angle when observing towers and trees are $60^{\circ}$ and $30^{\circ}$ respectively. The distance between the tip of the tower with the tip of the tree is?

(4) An observer was standing in a building. He saw another building with the peak observed at an angle of depression 60 , while the base at 30 . If the height of the building used to observe is 48 meters, the height of the observed building is?

\section{RESULTS AND DISCUSSION}

\section{A. Test Results of Math Word Problems on Trigonometry Application}

The study began by giving a scientific test of story-shaped questions to 189 students in three schools. After the question is tested, then analyzed to determine whether the score pass the minimum standard or not. The analysis results are shown on the following table (Table IV).

\begin{tabular}{ccccc}
\hline \multirow{2}{*}{ TABLE IV. } & \multicolumn{4}{c}{$\begin{array}{c}\text { TEST RESUlt OF MATH WORD PROBLEMS } \\
\text { TRIGONOMETRY APPLICATION }\end{array}$} \\
\cline { 2 - 4 } Score & \multicolumn{3}{c}{ School Category } & $\begin{array}{c}\text { Total of } \\
\text { Students }\end{array}$ \\
\cline { 2 - 4 }$\geq 75$ & 23 & 16 & 12 & 51 \\
$<75$ & 38 & 51 & 49 & 138 \\
Total of & 61 & 67 & 61 & 189 \\
\hline Students & & Medium & Low & \\
\hline
\end{tabular}

Based on Table IV, it can be seen that there are 51 students who passed and 138 students who have not passed. Students answers will be analyzed to find out the error in solving the math word problems. The following figure presents the written answers of each subject and analysis of the answer. For coding the student error in the written answer, NiSi code will be used, where " $\mathrm{N}$ " is the problem number error, " $\mathrm{S}$ " is the subject, and " $\mathrm{i}$ " is the sequence, $\mathrm{i}=$ $1,2,3 \ldots$ For example, N1S1 means "first number error in the first subject ".

1) Written Test Results and Problem Analysis No. 1 by Subject 1

a) Written Test Results N1S1

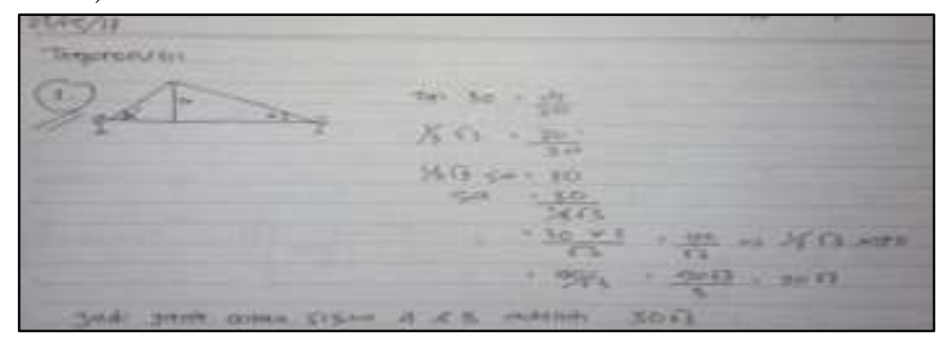

Fig. 1. Answer problem 1 By Subject 1

\section{b) N1S1 Analysis Written Test Results}

The answer of question number 1 shown that $S 1$ has been able to interpret the problem into of mathematical modeling quite well. However, when solving the problem with the calculation process, $S 1$ only stated the distance from the building to the first person. The distance of the building to the second person has not been mentioned. According to the researcher, $S 1$ has errors on calculating and analyzing aspects.

2) Written Test Results and Problem Analysis No. 2 by Subject 2

a) Written Test Results N2S2 


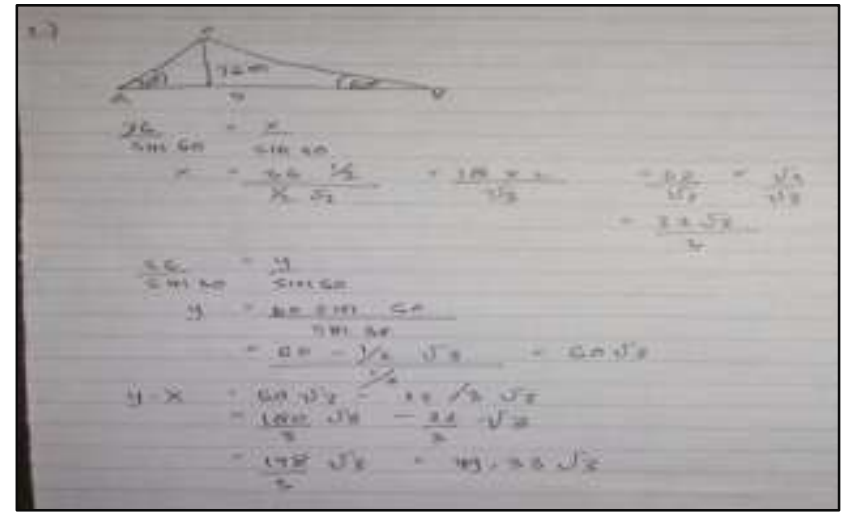

Fig. 2. Answer problem 2 By Subject 2

\section{b) N2S2 Analysis Written Test Results}

The question number 2 answer demonstrated that $S 2$ had difficulty in interpreting the story into the picture or mathematics modeling. It is supported by the $S 2$ inability to distinguish between the elevation angle and the angle of depression. Subject 2 drew the elevation angle in its work, whereas in the case of the desired angle is the angle of depression. According to the researcher, $S 2$ still faces errors in applying aspects of mathematical concepts.

3) Written Test Results and Problem Analysis No. 3 by Subject 3

a) Written Test Results N3S3

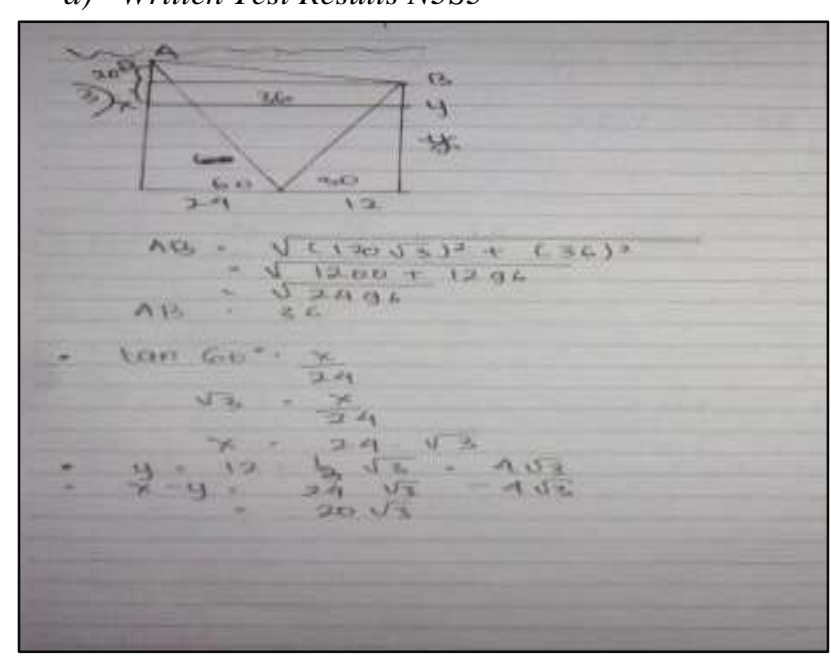

Fig. 3. Answer problem 3 By Subject 3

\section{b) N3S3 Analysis Written Test Results}

In the question number 3 answer, $S 3$ was able illustrate the story in the form of images or mathematical modeling. However, still, a little to be fixed neatness so that in solving the problem will be more explicit in analyzing the image. The calculations done by $S 3$ also look quite well. Its only the sequence of steps in the writing of the answer that must be considered. Subject 3 made an error in calculating the root that resulting in an error in the answer. According to the researchers, $S 3$ has difficulty doing calculations.

4) Written Test Results and Problem Analysis No. 4 by Subject 4 a) Written Test Results N4S4

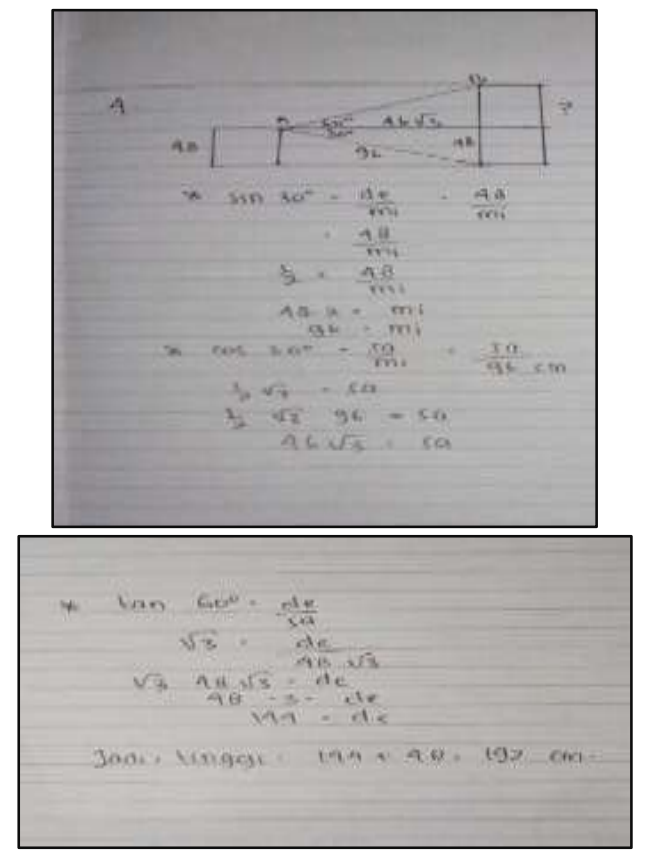

Fig. 4. Answer problem 4 By Subject 4

Fig. 5. . N4S4 Analysis Written Test Results

The question number 4 , subject 4 seemed still wrong in interpreting the story into the picture or mathematics modeling. It is reinforced by $S 4$ having a slight error in determining the angle of depression $60^{\circ}$ which also affects the writing of angles $30^{\circ}$, According to the researchers, $S 4$ experienced errors in scientific communication and aspects of doing calculations.

\section{B. Analysis of Interview Results}

To strengthen the assumption of analysis on the students' written work, the researcher reconfirmed with the students through interviews to the chosen subject.

1) Interview Result and Subject Analysis 1 (S1)

Based on the results of the interview, S1 had been able to interpret the story in the form of mathematical modeling. However, when performing the calculation operation, S1 only counted the first student's distance to the building, while the second student's distance to the building is not searched. It resulted an error in the calculation. He admited that he forgot to look for that distance. So according to the researchers, S1 had difficulty on performing calculations.

2) Interview Result and Subject Analysis 2 (S2)

Based on the results of interview, S2 was still having difficulty to interpret the story into the mathematical modeling. S2 also still couldn't distinguish between elevation angle and depression angle. S2 wrote the angle in its work as the elevation angle, whereas in the case of the desired angle is the angle of depression. According to the researchers, S2 still had difficulty in the aspects of applying mathematical concepts. Besides, S2 also experienced confusion in applying the formula used 
whether using a comparison of trigonometry, sinus rules, or cosine rules.

3) Interview Result and Subject Analysis 3 (S3)

Based on the results of the interview, S3 had been able to interpret the story into the form of mathematical modeling and even mathematical calculations, although it still had to be slightly fixed which work order should be done first. However, at the end of the work in solving a root calculation, S3 looked less thorough so that in the final step he made a mistake that resulted in any wrong answer in the matter.

\section{Interview Result and Subject Analysis 4 (S4)}

Based on the results of the interview, S4 was still having difficult to interpret the story into the picture or mathematical modeling. This was supported by S4 having a slight error in determining the angle of depression $60^{\circ}, \mathrm{S} 4$ instead wrote a corner $60^{\circ}$ as an elevation angle that also affects the writing of angles of $30^{\circ}$. Subject 4 acknowledged that having difficulty when determining the angle of depression to the picture, that caused the mathematics modeling became less precise.

\section{Triangulation of Test Analysis and Interview Results}

Based on the analysis of the written test and confirmed by the results of interviews with the four students, researchers get data about the mistakes experienced by students when solving the problem of application on the subject trigonometric divided into three types of errors, namely 1) difficulty in understanding the meaning of the problem, 2) difficulty applying concepts, and 3) difficulty in calculating.

\section{1) Error type I.}

Most students' mistakes when encountering a story are interpreting, imagining, and analyzing every intention of the problem sentences into their images or mathematical modeling. Many things that affect this problem, include the length of the word problem. Longer problem is usually harder for the student to understand. This error can be seen in question number 2 and number 4 which most students have difficulty. In this case, it is represented by subject 2 (S2) and subject 4 (S4). In problem 2, Subject 2 has difficulty in illustrating the problem in the form of its two vessels lying on the east side of the tower, S2 illustrated the two vessels facing each other. Furthermore, on written questions the known angle is the angle of depression, the S2 illustrates the mathematical model showing the elevation angle. It is also stressed by the results of interviews with the S2, that he confirmed having difficulty with it. In problem number 4 , Subject 4 was still wrong in interpreting the story into the picture or modeling mathematics. This confirmed by $\mathrm{S} 4$ that he was having difficulty to modeling the given word problem, that lead into a slight error in determining the angle of depression $60^{\circ}$.

\section{2) Error type II}

This aspect of error can be seen in number 2 on subject 2 (S2). Subject 2 was unable to distinguish between elevation angle and depression angle. He drew the angle, in his work, as elevation angle, whereas in the case of the desired angle is the angle of depression. According to the researchers, S2 had difficulty with aspects of applying mathematical concepts. In addition, S2 also when asked in the interview confirmed that he was experiencing confusion in applying the formula used whether to use a comparison of trigonometry, sinus rules, or cosine rules.

\section{3) Error type III}

This aspect of error can be seen in number 1 and number 3 on subject 1 (S1) and subject 3 (S3). In question number 1, S1 had been able to interpret the story in the form of mathematical modeling. However, when performing the calculation operation, S1 only calculated the distance of the first student to the building, while the second student distance to the building was not mentioned. This results an error in the calculation. Having confirmed through an interview with $\mathrm{S} 1$, he admitted that he forgot to look for that distance. So according to the researchers, S1 had difficulty on performing calculations. In question number 3, S3 has been able to interpret the story of the story into the form of mathematical modeling even mathematical calculations, although it still needed to be slightly fixed on the order of work. However, at the end of the work, S3 was less thoroughly calculating the root value so that in the final step he made a mistake that resulted in any wrong answer in the matter. This is confirmed correctly through interviews that $\mathrm{S} 3$ is less thorough in pulling square root.

Finally, the math word problems can be familiarized to the students by actively involve it the discussion to process knowledge building and utilize relevant resources to explore desired knowledge. It is by the opinions expressed by Bohan\&Bohan [18] that the learning process involving the active participation of students to solve various problems can present meaningful learning activities for students. Also, students become enthusiastic because they feel challenged for a given problem. It, of course, can increase students' motivation to learn. It is in line with Loewen's opinion [19] suggesting that challenging creative thinking can increase students' interest and motivation to learn. Thus, increased interest and motivation for student learning becomes a decisive factor for improving students' understanding of math word problems on trigonometry application

\section{CONCLUSION}

Based on the analysis of answers and interviews with students obtained some types of student errors in solving the story problem on the application of trigonometry include, error type I, understand the meaning of the problem. Most of the students' difficulties when encountering the story are the students having difficulty in interpreting, imagining, and analyzing every intention in the sentence into the picture or mathematical modeling. Many things that affect this include the problem is too long, less usually students find the story and difficulty in understanding the problem.

Error type II, applying the concepts. 1) Most students still can't distinguish between elevation angle and depression angle. Students tend to misplace between angle elevation and the angle of depression. It is closely related to 
the difficulties at the first point that students are still tricky in modeling mathematics on the matter of the story which resulted in difficulties also on applying the concept to the image to be used. 2) When a mathematical model or illustration drawing has been made, not a few students are confused about applying the formula to be used, whether using a comparison of trigonometry, sinus rules, or cosine rules.

Error type III, calculating. 1) Some students who have been able to model the story with the picture, and understand using the concept of working on the problem, but there are also some students who have miscalculations in the process of doing it. This problem was answered when the authors confirm by the interview that most students admitted less rigorous and in a hurry. 2) Some students whose work order is reversed. Steps that should take precedence, just students do it from predict answers, arrange steps progress.

\section{ACKNOWLEDGMENT (Heading 5)}

The Paper is made possible through help and support from parents, family, and friends. The author thanks Sebelas Maret University, local government and Three Schools in Gunungkidul regency who have given permission and opportunity for the research.

\section{REFERENCES}

[1] R.R. Skemp, "Thepsycology of learning mathematics", Victoria, Australia: Penguinbooks Australia ltd, p 37, 1971.

[2] L. Verschaffel, B. Greer, and E. D. Corte, "Making Sense of Word Problems," Lisse, The Netherlands: Swets and Zeitlinger, 2000

[3] M. S. Riley and J. G. Greeno, "Developmental analysis of understanding language about quantities and ofsolving problems," Cognition and Instruction, vol. 5(1), pp. 49-101, 1988.

[4] B. Greer, "Multiplication and division as models of situations," in Handbook of Research on Mathematics Education, D. Grouws, ed. New York: Macmillan, pp. 276-295, 1992.

[5] Littlefield and J. J. Rieser, "Semantic features of similarity andchildrens' strategies for identification ofrelevant information in mathematical story problems," Cognition and Instruction, vol. 11, pp. 133-188, 1993.

[6] R. E. Mayer, Mathematical ability, in Human Abilities: An Information Processing Approach, R. J. Sternberg, ed., San Francisco: Freeman, pp. 127-150, 1985.

[7] E. A. Silver, "Research on teaching mathematical problem solving: someunder represented themes andneeded directions," in Teaching and Learning Mathematical Problem Solving, Multiple Research Perspectives, E. A. Silver, ed., Hillsdale, NJ.: Lawrence Erlbaum, pp. 247-266, 1985.

[8] J. Langeness, "Methods to Improve Student Ability in Solving Math Word Problems". St. Paul, MN: Hamline University, (2011).

[9] B. Krick-Morales, "Reading and understanding written math problems." Retrieved on August 3 (2006): 2012. http://www.colorincolorado.org/article/reading-and-understandingwritten-math-problems

[10] T. Thompson, "Mathematics Teacher's Interpretation of Higher-order Thinking in Bloom's Taxonomy," International Electronic Journal of Mathematics Education, vol.3(2),pp. 96-109 (Online), 2008

[11] A. Lewis \& D. Smith, "Defining higher order thinking," Theory into practice Vol. 32(3), pp. 131-137, Summer. College of education, The Ohio State University, 1993.

[12] R.J. Marzano,\& J.S. Kendall, The New Taxonomy of Educational Objectives. Corwin Press, 2006.

[13] Lewy, Zulkardi, N Aisyah, Higher Order Thinking Skill:Jurnal Pendidikan Matematika, 3(2) pp 14-28, 2009.

[14] M. Pohl, Learning to Think, Thinking to Learn: Models and Strategies to Develop a Classroom Culture of Thinking, New York: Hawker Brownlow Education, p 98, 1999.

[15] D.R. Krathwohl, A Revision of Bloom's Taxonomy: An Overview. Theory Into Practice, Vol. 41(4). College of Education: The Ohio State University, 2002.

[16] Tim Penyusun. Kamus Bahasa Indonesia. Jakarta: Pusat Bahasa Departemen Pendidikan Nasional, 2008.

[17] M, Porwanto, "Analisis Kesalahan Siswa dalam Menyelesaikan Masalah Matematika Bentuk Soal Cerita pada Pokok Bahasan Peluang SMA Tribhakti Tanggulangin Kelas XII IPS”. Jurnal Pendidikan Matematika STKIP PGRI Sidoarjo Vol. 2(3). Sidoarjo, 2014.

[18] H. Bohan H \& S. Bohan, The Arithmetic Teacher4183-87, 1993.

[19] C.A. Loewen, "Creative problem solving." Teaching Children Mathematics 2, no. 2 (1995): 96-99. 